\title{
KONTEKSTUALISASI KEBIJAKAN PENGEMBANGAN KOLEKSI DALAM MEMENUHI KEBUTUHAN INFORMASI PENGGUNA (Studi Kasus di Perpustakaan UIN Sunan Kalijaga Yogyakarta)
}

\author{
Iskandar \\ Jurusan Ilmu Perpustakaan, Fakultas Ilmu Sosial dan Ilmu Politik \\ Universitas Muhammadiyah Mataram \\ Iskandarngali94@gmail.com
}

INFO ARTIKEL
Riwayat Artikel:
Diterima:...-...-...
Disetujui:...-...-...

\section{Kata Kunci:}

Kontektualisasi, pengembangan koleksi, pemustaka

\begin{abstract}
ABSTRAK
Penelitian ini berjudul Kontekstualisasi Kebijakan Pengembangan Koleksi dalam memenuhi kebutuhan informasi pengguna : Studi kasus di perpustakaan Univeristas Islam Negeri Sunan Kalijaga Yogyakarta, peneliti menganalisis bagaimana kontekstualisasi kebijakan pengembangan koleksi dilhat dari kebijakan yang dikeluarkan oleh pengelola perpustakaan Univeristas Islam Negeri Sunan Kalijaga Yogyakarta. Penelitian ini bertujuan untuk menjelaskan bagaimana kontekstualisasi kebijakan pengembangan koleksi dapat berdampak pada kesesuaian informasi yang sediakan bagi pengguna di Perpustakaan UIN Sunan Kalijaga Yogyakarta. Penelitian ini menggunakan metode penelitiaan kualitatif dengan pendekatan deskriptif. Dari hasil penelitian yang dilakukan oleh peneliti, maka hasilnya adalah kontekstualisasi kebijakan pengembangan koleksi yang dilakukan oleh perpustakaan Univeristas Islam Negeri Sunan Kalijaga Yogyakarta belum maksimal, dikarenakan pengelola perpustakaan Univeristas Islam Negeri Sunan Kalijaga Yogyakarta belum diberikan wewenang penuh dalam pengelolaan anggaran perpustakaan.
\end{abstract}

Abstract:

This study titled Contextualization of Collection Development Policy to fulfill the information need of users: A case study in the library of State Islamic University of Sunan Kalijaga Yogyakarta, researcher analyzed how contextualization of collection development policy of the Library of State Islamic University of Sunan Kalijaga have an impact to the suitability of information served to the users. This study uses qualitative descriptive approach. From the results of research conducted by the researcher, the result is the contextualization of collection development policy carried out by the Library of State Islamic University of Sunan Kalijaga Yogyakarta, is not maximized, because the librarian have not been given full authority in the management of the library budget.

\section{A. PENDAhuluan}

Kehadiran perpustakaan perguruan tinggi sejatinya merupakan bentuk dari kesiapan lembaga pendidikan dalam memenuhi hak informasi bagi para mahasiswa dan civitas akademika demi lancarnya proses pendidikan. Perpustakaan perguruan tinggi dituntut untuk bergerak cepat dalam menyesuaikan tren informasi yang berkembang dengan kebutuhan pengguna agar akselearasi pendidikan di perguruan tinggi berjalan secara dinamis. Kesiapan perpustakaan dalam memberikan informasi merupakan bagian dari kontektualisasi eksistensi perpustakaan sebagai institusi yang memegang kendali penuh dalam pengadaan, pengolahan, dan penyebaran luasan informasi.

Dalam menopang tersedianya informasi yang berkualitas, perpustakaan perguruan tinggi menjadikan kegiatan pengembangan koleksi sebagai sentra dalam mendesain, merancanakan, dan menuntukan sumber-sumber informasi yang tepat, agar terjadi keselarasan antara fungsi perpustakaan dan perguruan tinggi sebagai lembaga induk yang menaungi perpustakaan. Sehingga lembaga induk dimana perpustakaan bernaung wajib mengalokasi dana yang cukup pada perpustakaan agar dapat 
mendukung terlaksanannya kebijakan pengembangan koleksi yang sesuai kebutuhan pengguna, hal ini terjadi pada setiap perpustakaan perguruan tinggi. Di perpustakaan UIN Sunan Kaliga Yogyakarta perpustakaan Universitas mendapatkan 1 Milyar lebih yang dilakokasi dari dana APBN.

Melihat jatah anggaran yang diberikan, institusi perpustakaan harus mampu mengalokasikan secara tepat dengan melakukan pengadaan informasi yang benar-benar sesuai kebutuhan. Karena kebijakan pengembangan koleksi juga merupakan rencana utama untuk membangun dan menjaga koleksinya. Menurut Evan (2000 : 6970) Kebijakan pengembangan koleksi harus mencerminkan dan berhubungan dengan perencanaan perpustakaan khususnya dalam jangka panjang dan strategis.

Agar proses perencanaan dalam pengembangan koleksi bisa berjalan dengan baik, Perpustakaan UIN Sunan Kalijaga juga harus membuat kerangka tertulis yang baku untuk dijadikan sebagai acuan yang menjadi bagian dari kontekstualisasi fungsi perpustakaan. Menurut Bonk (1979 : 71) keputusan mengenai cara pengembangan koleksi yang dicantumkan tertulis merupakan dasar untuk perencanaan operasional perpustakaan yang lebih luas. Sebagai institusi yang tidak berdiri sendiri, dalam setiap pengambilan keputusan dalam rangka pengembangan koleksi, perpustakaan selalu berangkat pada kondisi internal.

Menurut Magrill (1989 :16) faktor internal yang mempengaruhi proses pengembangan koleksi dapat dijabarkan menjadi lima hal, yaitu masyarakat atau institusi, tujuan perpustakaan, kelompok masyarakat atau pemakai yang harus dilayani, koleksi yang telah ada, sumber daya yang tersedia yang meliputi sumber daya manusia, dana, bahan yang tersedia, serta alat bantu untuk identifikasi dan evaluasi yang tersedia. Dalam pengembangan koleksi perlu dilakukan pengkajian secara mendalam baik secara toeritis maupun teknis agar kebijakan yang dikeluarkan sesuai dengan kebutuhan informasi yang menjadi perioritas dari pengguna.

Pembahasan dalam penelitiaan ini difokuskan untuk mengatahui sejauh mana kontekstualisasi kebijakan pengembangan koleksi yang dilakukan di Perpustakaan UIN Sunan Kalijaga Yogyakarta. Pada akhirnya penelitiaan diharapakan menjadi role model, mengingat selama ini kajian tentang kebijakan pengembangan koleksi masih bersifat pada tataran teknis, belum menyentuh pada ranah toeritis dan filosifis.

Penlitian menggunakan metode kualitatif dimana menurut Maleong (2005: 6) yaitu, penelitian kualitatif adalah penelitian yang digunakan untuk memahami fenomena yang dialami oleh subjek penelitian, seperti perilaku, persepsi, motivasi, tindakan, dan lain sebagainya secara holistik, dan dalam bentuk deskripsi kata-kata mengenai suatu konteks tertentu yang alamiah, serta menggunakan metode yang alamiah. Adapun jenis penelitian yang digunakan adalah studi kasus. Basuki (2006:13) mengatakan bahwa, studi kasus merupakan kajian mendalam tentang peristiwa, lingkungan, dan situasi tertentu yang memungkinkan mengungkapkan atau memahami suatu hal. Teknik pengumpulan data yang dilakukan dalam penelitan adalah dengan cara observasi, dokumentasi, dan wawancara dengan orang-orang yang dianggap memiliki pemahaman tentang pengembangan koleksi di perpustakaan UIN Sunan Kalijaga Yogyakarta.

\section{B. LANDASAN TEORI}

\section{Pengembangan Koleksi}

Pengembangan koleksi di suatu perpustakaan merupakan salah satu kegiatan yang wajib dilaksanakan guna untuk menentukan kebutuhan informasi yang tepat yang perlu disediakan bagi pengguna. Menurut Elder (1990 :444), pengembangann koleksi 
merupakan suatu kerja inteıектual yang sistematis dalam menetapkan kebutuhan informasi yang akan diperoleh perpustakaan, berkenaan dengan misi atau rencana strategis yang dirumuskan dengan baik. Sedangkan menurut Evans (2000) dalam Triana Santi (2010:3) memberikan batasan istilah "collection development" sebagai suatu proses untuk mengetahui peta kekuatan dan kekurangan atau kelemahan koleksi perpustakaan, sehingga dengan demikian akan tercipta sebuah planning untuk memperbaiki peta kelemahan tadi dan mempertahankan kekuatan koleksi. ia merupakan serangkaian kegiatan yang saling berhubungan dan lebih luas dari sekedar pengadaan bahan pustaka. Namun demikian dapat dinyatakan bahawa kegiatan pengadaan merupakan ujung tombak dari kegiatan pengembangann koleksi.

\section{Kebijakan Pengembangann Koleksi}

Berkaitan dengan kebijakan (policy), menurut Johnson (2009 : 72), kebijakan pengembangann koleksi sering disebut juga dengan kebijakan seleksi, pernyataan (statements) koleksi, atau perencanaan pengembangann koleksi. Kebijakan ini merefleksikan realitas perencanaan untuk membangun dan memelihara koleksi baik yang diperoleh secara lokal (intern perpustakaan) maupun yang diakses secara jarak jauh (remotely). Secara garis besar, kebijakan ini berisi tujuan dan audiens (kepada siapa kebijakan ditujukan). Tujuan dari kebijakan ini dibagi menjadi dua kategori, yaitu untuk informasi dan untuk menjaga. Menurut Evans dan Saponaro (2005 :5), kebijakan pengembangann koleksi adalah proses memastikan bahwa kebutuhan informasi masyarakat perpustakaan (pengguna) akan informasi terpenuhi secara tepat waktu dan ekonomis dengan menggunakan sumber-sumber informasi yang dihasilkan baik di dalam maupun di luar perpustakaan.

Secara umum pengembangann koleksi menurut Darmono (2001 : 49-50) perlu rujuk kepada prinsip-prinsip pengembangann koleksi yaitu sebagai berikut: 1) Relevansi

Artinya aktifitas pemilihan dan pengadaan terkait dengan program pendidikan yang disesuaikan dengan kurikulum yang ada. Berorientasi kepada pemakai. Dengan demikian kepentingan pengguna menjadi acuan dalam pemilihan dan pengadaan bahan pustaka.

2) Kelengkapan

Koleksi Perpustakaan diusahakan tidak hanya terdiri dari buku teks yang langsung dipakai untuk mata pelajaran yang diberikan tetapi juga menyangkut bidang ilmu yang berkaitan erat dengan program yang ada dalam kurikulum. Semua komponen koleksi mendapatkan perhatian yang wajar sesuai dengan tingkat prioritas yang ditentukan.

3) Kemutakhiran

Disamping memperhatikan maslah kelengkapan, kemutakhiran sumber informasi harus diupayakan sesuai dengan perkembangan ilmu pengetahuan. Kemutakhiran bahan pustaka dapat dilihat dari tahun terbit. Jika bahan pustaka diterbitkan pada tahun terakhir, maka dapat dilihat dari kemutakhiran dapat katakana mutakhir.

4) Kerjasama

Unsur-unsur yang terkait dalam pembinaan koleksi harus ada kerjasama yang baik dan harmonis sehingga pelaksanaan kegiatan pembinaan koleksi berjalan efektif dan efesien. Kerjasama ini melibatkan semua komponen yang 
terlibat dalam pembinaan koleksi seperti kepala perpustakaan, petugas perpustakaan atau pustakawan, guru, serta pihak yang mengadakan pembelian.

\section{Kebutuhan Informasi}

Kebutuhan informasi merupakan salah satu kebutuhan dasar yang dibutuhkan oleh manusia. Posisi informasi dalam kehidupan manusia memegang peranan penting. Tampa informasi institusi perguruan tinggi tidak akan mampu menjalankan tridharma perguruan tinggi dalam hal pengajaran, penelitian, dan pengabdian pada masyarakat. Kebutuhan informasi menurut Lasa H.S (2009 : 150) adalah :

"Kebutuhan yang didasarkan pada dorongan untuk memahami, menguasai lingkungan, memuaskan keingin-tahuan / curiosity, dan penjelajahan / exploratory. Kemudian informasi diperoleh dari sumber informasi dapat digunakan untuk 1) menambah pengalaman; 2) memperoleh informasi mutakhir; 3) memperoleh pengetahuan sesuai kebutuhan; 4) mengembangkan diri."

Sedangkan menurut Wersig dalam Suwanto (2013), kebutuhan informasi adalah segala tindakan manusia yang didasarkan pada sebuah gambaran baik tentang lingkungannya, pengetahuannya, maupun situasi dan tujuan yang ada pada diri manusia. Jadi dapat disimpulkan bahwa kebutuhan informasi merupakan satu keharusan yang dimiliki oleh setiap manusia dalam mendukung segala aktivitasnya baik sebagai seorang individu maupun dalam rantai sosial. Sedangkan Yusuf (2010 : 91), setiap orang dalam kehidupannya memiliki kebutuhan informasi yang berbedabeda. Hal ini disebabkan oleh kondisi sosiologis, kognitif, maupun situasi dimana seseorang itu berada. Misalnnya jika individu berfikir tentang upaya bagaimana caranya untuk meningkatkan kemampuan diri, maka ia akan berfikir tentang upaya bagaimana mencari informasi dan melalui media komunikasi apa yang harus digunakan untuk mencapai tujuan tersebut.

\section{Gambaran Umum Perpustakaan UIN Sunan Kalijaga Yogyakarta.}

Perpustakaan UIN Sunan Kalijaga Yogyakarta memiliki riwayat yang panjang dalam berdirinya. Keberadaanya tidak bisa dipisahkan dari lembaga induk yang menaunginya, yaitu Perguruan Tinggi Agama Islam Negeri (PTAIN) yang didirikan pada tanggal 26 September 1951 berdasarkan PP No. 34 Tahun 1950. Baru pada tanggal 24 Agustus 1960 berdasarkan PP No. 11 Tahun 1960 PTAIN Yogyakarta digabungkan dengan Akademi Dinas Ilmu Agama (ADIA) Jakarta menjadi Institut Agama Islam Negeri (IAIN), al-Jami'ah al-Islamiyah alHukumiyah, di Yogyakarta. Kemudian IAIN Sunan Kalijaga berubah menjadi Universitas Islam Negeri (UIN) Sunan Kalijaga pada tanggal 14 Oktober 2004 berdasarkan Keputusan Presiden No.50 Tahun 2004

Perpustakaan UIN Sunan Kalijaga mengalami perkembangan sejalan dengan perkembangan lembaga induknya. Setelah keluarnya Keputusan Menteri Agama No. 14 Tahun 1988 posisi perpustakaan yang semula secara struktural berada di bawah Sekretaris Institut, berubah menjadi Unit Pelaksana Teknis (UPT) Perpustakaan yang secara struktural berada langsung di bawah Rektor.

Visi Perpustakaan UIN Sunan Kalijaga Yogyakarta adalah "Mengembangkan Perpustakaan UIN Sunan Kalijaga sebagai perpustakaan penelitian berbasis keislaman dan keilmuan”. Untuk Misi Perpustakaan adalah:

1. Mengembangkan sumber-sumber belajar yang unggul dalam bidang keislaman dan keilmuan.

2. Meningkatkan akses ke sumber-sumber penelitian dalam bidang keislaman dan keilmuan berbasis teknologi informasi.

3. Meningkatkan kualitas layanan prima yang sesuai dengan perkembangan teknologi informasi. 
4. Memperkuat hubungan kerja sama dengan lembaga terkait untuk meningkatkan akses ke sumber-sumber yang relevan.

Struktur organisasi di Perpustakaan UIN Sunan Kalijaga Yogyakarta sebagai berikut: Kepala Perpustakaan UIN dijabat oleh Dra. Labibah, MLIS, sedangkan wakilnya dijabat oleh Sri Astuti, SIP. MIP. Dibawah wakil ada tiga Kabid (Kepala bidang) yaitu Kabid Layanan Pengguna, Kabid Layanan Teknis dan Kabid Layanan Teknologi Informasi. Dibawah kepala bidang tersebut, dibentuk tujuh kepala urusan (KAUR) yaitu Kaur Sistem Informasi dan Jaringan, Kaur Repositori Jaringan, Kaur Pengembangan dan Pemeliharaan Koleksi, Kaur Sistem Informasi dan Jaringan, Kaur Pengolahan Bahan Pustaka, Kaur Repository Digital, Kaur Referensi dan Serial, dan Kaur Sirkulasi. Kepala urusan tersebut dibentuk bertujuan untuk memebantu kepala perpustakaan dalam menangani urusan internal yang bersifat teknis dalam aktivitas perpustakaan.

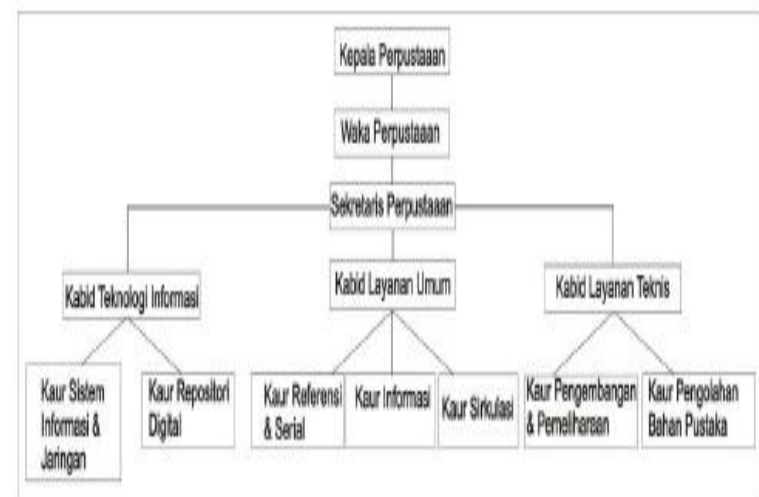

D. Kontekstualisasi Kebijakan pengembangan koleksi di Perpustakaan UIN Sunan Kalijaga Yogyakarta.

\section{Kebijakan Pengambangkan Koleksi Perpustakaan UIN Sunan Kalijaga Yogyakarta.}

Perpustakaan UIN Sunan Kalijaga Yogyakarta sebagai sentral kegiatan mahasiswa memegang tanggunjawab yang sangat penting. Agar eksistensi perpustakaan tetap terjaga maka perpustakaan harus melakukan pengembangan koleksi yang memadai. Hal senada dengan apa yang disampaikan oleh Rowley (1996 : 9), dimana dikatakan bahwa prinsipnya pengembangan koleksi akan terus menjadi bagian yang terpenting dalam perpustakaan, baik pada masa lalu, saat ini, maupun masa yang akan datang. Karena pengembangan koleksi sebagaimana dengan perpustakaan akan terus beradaptasi mengikuti perubahan yang ada.

Di Perpustakaan UIN Sunan Kalijaga Yogyakarta pengembangan koleksi dilakukan secara konsisten dan berkala dalam setiap tahunnya. Hal sejalan seperti apa yang disampakan oleh salah satu narasumber yang peneliti wawancarai.

"Setiap tahunnya kami di perpustakaan melakukan pengadaan bahan pustaka, dan itu kami sesuaikan dengan kebutuhan dari pengguna. Kami juga melakukan evaluasi dengan mengirim surat pada tingkat fakultas, dan menyediakan kotak saran bagi pengguna yang ingin memberikan saran tetang buku-buku yang dibutuhkan" (Wawancara, tanggal 18/10/2016, 09.00 WIB)

Gambaran yang disampaikan oleh informan di atas mencerminkan bahwa perpustakaan UIN Suka melakukan akselerasi guna menyesuiakan informasi yang disediakan dengan kebutuhan pengguna. Dalam melakukan kebijakan pengembangan koleksi perpustakaan

Dilain pihak guna mendukung proses pengembangan koleksi perpustakaan berjalan secara baik, pihak Perpustakaan UIN Sunan Kalijaga Yogyakarta juga memaksimalkan posisi dosen-dosen dan mahasiswa yang ada. Hal ini sejatinya merupakan langkah yang baik dalam menyesuaiakan informasi yang dibutuhkan dengan apa yang dibelanjakan oleh pihak perpustakaan. Tapi hal ini tidak berjalan secara maksimal mengingat respon dari pihak fakultas dan respon mahasiswa yang berkunjung ke perpustakaan terkadang tidak terlalu baik. Kondisi ini seperti apa yang dipaparkan oleh salah satu informan yang peneliti wawancarai. 
"kami dari perpustakaan tetap melakukan pemberitahuan kepada pihak fakultas untuk memberikan masukan, ya tapi begitulah banyak juga yang tidak merespon surat yang kami sampaikan, mahasiswa juga terkadang kurang respon, karena mereka kalau ke perpustakaan jarang bertanya ke petugas". (Wawancara, tanggal 18/10/2016, 10.00 WIB)

Apa yang disampaikan oleh informan ini semakin menegasikan bahwa perpustakaan secara fungsi sudah berusaha untuk bekerjasama dengan pihak-pihak yang menjadi objek informasi di perpustakaan. Walapun hasil di dapatkan belum sepenuhnya maksimal sesuai dengan target yang diharapkan oleh pihak. Dampak dari pada kondisi ini akan berimplikasi pada kesusuaian informasi yang ada di perpustakaan dengan kebutuhan pengguna kedepannya.

\section{Kontekstualisasi Kebijakan Pengembangan Koleksi di Perpustakaan UIN Sunan Kalijaga Yogyakarta.}

Kebutuhan informasi pengguna akan terpenuhi dengan baik apabila perpustakaan konsisten melalukan pengembangan koleksi dengan melakukan koordinasi dan komunikasi dengan pengguna secara masif. Pengembangan koleksi akan menjadi pilar dalam pembaharuan informasi di perpustakaan ketika roh informasi yang disediakan sesuai dengan apa yang diharapkan oleh pengguna. Pada poin inilah kontekstualisasi kebijakan dalam pengembangan koleksi di Perpustakaan UIN Sunan Kalijaga menjadi urgen untuk dikaji aplikasikan.

Kontekstualisasi dimaksudkan agar kebijakan pengembangan koleksi yang dilakukan oleh pihak Perpustakaan tidak mengabaikan asas kebutuhan dari pengguna yang sejati memiliki hak penuh atas informasi yang disediakan oleh pihak perpustakaan. Kontekstualsasi akan maksimal apabila didukung oleh keselarasan pemahaman diantara pemangku kebijakan, baik pada tingkat perpustakaan maupun di lembaga induk yang menaungi perpustakaan yaitu Universitas. Kenyataannya, keselarasan komunikasi ini belum terlaksananya dengan baik.

Dimana perpsutakaan belum sepenuhnya diberikan kuasa penuh dalam dalam hal pengambilan kebijakan, misalnya lelang, promosi, kerjasama, dan pembentukan corner. Hal ini sejalan dengan hasil penelitian Ardiawin dkk (2016 : 14) mahasiswa Program Pascasarjana Konsertarasi Ilmu Perpustakaan dan Informasi UIN Sunan Kalijaga Yogyakarta sebagai berikut :

"Di Perpustakaan UIN Sunan Kalijaga Yogyakarta serat akan kepentingan-kepentingan para penguasa, kekuasaan tersebut terepresentasi dalam kegiatan lelang, promosi, kerjasama dan pembentukan corner. Pada kegiatan lelang perpustakaan tidak memiliki kuasa penuh. Kuasa perpustakaan hanya sebatas memberi data daftar dan menyeleksi koleksi apa saja yang akan dibeli, sedangkan penentuan peserta dan pemenang lelang perpustakaan tidak ikut andil. Peserta lelang yang tidak lolos seleksi disebabkan karena administrasi yang kurang. Pada kegiatan promosi, meskipun ada beberapa aktor yang merekomendasikan produk tertentu untuk dibeli atau dilanggan pihak perpustakaan, kuasa untuk penentuan pembelian atau melanggan tersebut tetap ada pada pimpinan perpustakaan. Sedangkan dalam hubungan kerjasama dan Corner pustakawan tidak memiliki kuasa dalam menyeleksi buku yang akan di adakan, karena sudah adanya ketentuan dari atasan atau pihak yang memiliki kuasa"

Merujuk pada hasil penelitian ini, menujukan bahwa perpustakaan belum sepenuhnya memegang otonomi secara penuh dalam pengelolaan perpustakaan. Penelitian ini memperlihatkan bahwa kontekstualisasi kebijakan pengembangan koleksi tidak berjalan secara maksimal. Ketika permasalahan ini terus menerus terjadi maka akan menimbulkan disharmonisasi antara pihak Universitas selaku lembaga induk perpustakaan bernaung dengan kepentingan informasi pengguna yang menjadi tanggunjawab perpustakaan secara institusi.

Lebih lanjut hasil hal sama juga dikonfirmasi oleh pihak yang bertanggungjawab dalam pengembangan koleksi di Perpustakaan UIN Sunan Kalijaga yang peneliti wawancarai sebagai berikut :

"Kami dari pengelola perpustakaan tidak memiliki wewenang penuh dalam penenutuan anggaran, 
kami hanya bisa mengusulkan pada pihak Universitas, bagaimananya itu tergantung dari pihak universitas". ((Wawancara, tanggal 18/10/2016, 10.45 WIB)

Disamping tidak ada adanya kuasa penuh Perpustakaan dalam menentukan roda pengendalian perpustakaan. Perpustakaan UIN Sunan Kaliga pada prinsipnya, dengan keterbatasan kekuasan yang dimiliki bisa membentuk tim khusus yang bertanggungjawab dalam memantau tren perkembangan informasi yang ada. Agar pada saat pembicaraan pengembangan koleksi sudah memiliki data akurat. Akan tetapi hal ini belum dilakukan di Perpustakaan UIN. Seperti yang disampaikan oleh salah satu informan berikut ini :

"Sejauh ini tim khusus yang bertugas menganalisis tren perkembangan informasi belum ada, kami biasanya pada awal keluarnya anggaran baru, akan membahas kebutuhan-kebutuhan informasi yang perlu diadakan di perpustakaan, pada dasarnya keberadaan tim khusus saya sih setuju akan membantu kerja bagian pengembangan koleksi kedepannya" (Wawancara, tanggal 18/10/2016, 10.45 WIB)

Keberadaan tim khusus yang menganalisis tren perkembangan informasi akan memudahkan terlaksananya kontekstualisasi kebijakan pengembangan koleksi yang bisa seirama dengan aspek kebutuhan informasi pengguna. Ketika kontekstualisasi ini bisa dilakukan eksistensi perpustakaan akan semakin terjaga, keselarasan informasi yang disediakan dengan kebutuhan pengguna akan sekamin meyakinkan pengguna akan betapa pentingnya perpustakaan dalam pemenuhan kebutuhan informasi di perguruan tinggi.

\section{E. Simpulan}

Dalam melakukan kontekstualisasi kebijakan pengembangan koleksi Perpustakaan UIN Sunan Kalijaga Yogyakarta perlu melakukan komunikasi yang lebih masif guna membangun kesepahaman dengan lembaga induk tempat perpustakaan bernaung, sehingga tanggungjawab yang diemban oleh perpustakaan sebagai institusi yang memegang kendali penuh dalam penyediaan, pengolahan, dan penyebarluasan informasi di perguruan tinggi tidak tercederai dengan adanya komunikasi yang kurang efektif. Kontekstualisasi dibutuh agar informasi yang disediakan oleh perpustakaan memiliki kesusuaian dengan kebutuhan informasi pengguna, yang tidak mengabaiakan tren perkembangan informasi terkini. Ketika kontekstualisasi berhasil dilakukan maka eksistensi perpustakaan akan semakin terjaga, serta meningkatkan kepercayaan dari pengguna akan posisi perpustakaan penopang utama terlaksanannya pendidikan di perguruan tinggi.

\section{Daftar Pustaka}

Bonk, Waller dan Magrill, Rose Mary.1979. Building Library Collection, 5th ed. Methuchen : Scarecrow.

Evans, G. Edward . 2000. Developing library and information center collection. Littleton, Colorado : Libraries Unlimited.

Darmono. 2001. Manajemen dan Tata kerja Perpustakaan Sekolah, (Jakarta: PT Gramedia Widia Sarana Indonesia.

G. Edward Evans dan Margaret Zarnosky Saponaro. 2005. Developing Library and Information Center Collections 5th Ed. London: Libraries Unlimited.

Gordon Rowley \& William K. Black. 1996. Consequence of Change : The Evolution of Collecction Development . (emerald Insight, 1996).

Lasa Hs. 2009. Kamus Kepustakawanan Indonesia. Yogyakarta: Pustaka Book Publisher.

Lexy J. Moleong. 2009. Metodologi Penelitian Kualitatif. Bandung: PT Remaja Rosdakarya.

Iwin Ardiawan dkk. 2016). Pengaruh Kuasan dalam Pengembangan Koleksi di Perpustakaan UIN Sunan Kalijaga Yogyakarta. (Makalah tidak diterbitkan) 
Magrill, Rose Mary and John Corbin. 1989. Acquistions Management Collections Development in Libraries. America Library Associations : Chicago.

Nelda J Elder, et al. 1980. Collection Development, selection, and Acquition of Agricultural material", Library Trend. 38 (3). 45

Pawit M. Yusup dan Priyo Subekti. (2010). Teori dan Praktik Penelusuran Informasi (Information Retrieval). Jakarta: Kencana

Peggy Johnson. 2009. Fundamentals of Collection Development and Management 2nd Ed. Chicago: American Library Association.

Triana Santi. 2010. Manajemen Koleksi (Collection Management) Kebijakan Pengembangann Koleksi Perpustakaan Perguruan Tinggi. Jurnal Iqra' Mei 210, Vol. 04 No.01. hlm, 3. Diakses pada tangal 4 Desember 2015 pada

alamat repository.usu.ac.id/bitstream/123456789/1782 /1/o8E00508.pd

Shavelson dan Townes dalam Yin Robert K. 2003. Case Study Research: Design and Methods. London: SAGE Publication,, - Ed. 3 (5) 2003)

Sri Ati Suwanto, "Kebutuhan dan Perilaku Pencarian Informasi Dosen Fakultas Kedokteran Undip dan Unissula Semarang" dalam http://eprints.undip.ac.id/19618/1/sriatitesis. pdf diakses pada 10 Desember 2016

Sulistyo-Basuki. (2006). Metode Penelitian. Jakarta: Wedatama Widya Sastra. http://uin-suka.ac.id 